\title{
A comprehensive analysis of various structural parameters of Indian coals with the aid of advanced analytical tools
}

\author{
B. Manoj $\mathbf{1}^{1}$
}

Received: 23 November 2015/Revised: 3 May 2016/Accepted: 8 June 2016/Published online: 30 June 2016

(C) The Author(s) 2016. This article is published with open access at Springerlink.com

\begin{abstract}
An exhaustive structural analysis was carried out on three Indian coals (ranging from sub-bituminous to high volatile bituminous coal) using a range of advanced characterization tools. Detailed investigations were carried out using UV-Visible spectroscopy, X-ray diffraction, scanning electron microscopy coupled energy dispersive spectroscopy, Raman spectroscopy and Fourier transform infrared spectroscopy. The X-ray and Raman peaks were deconvoluted and analyzed in details. Coal crystallites possess turbostratic structure, whose crystallite diameter and height increase with rank. The $\mathrm{H} / \mathrm{C}$ ratio plotted against aromaticity exhibited a decreasing trend, confirming the graphitization of coal upon leaching. It is also found that, with the increase of coal rank, the dependency of $I_{20} / I_{26}$ on $L_{a}$ is saturated, due to the increase in average size of $\mathrm{sp}^{2}$ nanoclusters. In Raman spectra, the observed $\mathrm{G}$ peak $\left(1585 \mathrm{~cm}^{-1}\right)$ and the D2 band arises from graphitic lattices. In IR spectrum, two distinct peaks at 2850 and $2920 \mathrm{~cm}^{-1}$ are attributed to the symmetric and asymmetric $-\mathrm{CH}_{2}$ stretching vibrations. The intense peak at $\sim 1620 \mathrm{~cm}^{-1}$, is either attributed to the aromatic ring stretching of $\mathrm{C}=\mathrm{C}$ nucleus.
\end{abstract}

Keywords Coal structure $\cdot$ Spectroscopic tools $\cdot$ X-ray diffraction $\cdot$ Graphene layers

\section{Introduction}

Coal, being primary source of energy is essential for living and sustainable advancement of any nation. Besides this, it is utilized as an important and imperious reserve for the manufacture of products like creosote oil, naphthalene, phenol and benzene. Materials like activated carbon, carbon blacks and electrodes, have been synthesized from coal (Zhou et al. 2012). Compared with crystalline carbon allotropes, so-called lattice solids, such as graphite and diamond that have found applications in areas such as microelectronics, optoelectronics and biomedicine. The crystalline carbon within the coal structure consists of abundant irregular, polymerized aromatic

B. Manoj

manoj.b@christuniversity.in

1 Department of Physics, Christ University, Bangalore, Karnataka 560027, India hydrocarbon units, such as angstrom- or nanometer-sized crystalline carbon domains that are joined by weak crosslinks. As coals possess many poly-aromatic structures similar to $\mathrm{sp}^{2}$ bonding character of graphene, they are used as precursors for the production of nanomaterials. With the advent of carbon nano-structures, scientific research on coal based products have recently received ever-increasing attention (Geim 2009; Li et al. 2006; Zhou et al. 2012; Binoy et al. 2009; Das et al. 2016; Manoj and Kunjomana 2014). Zhou et al. (2012) derived graphene and graphene-noble metal composites with anthracite coal as precursor by catalytic graphitization. Dong et al. (2014) synthesized graphene quantum dots, carbon dots and graphite nanocrystals from different coals with chemical oxidation and series of centrifugation. A facile method to synthesis tunable graphene quantum dots from coal by chemical oxidation and sonication was reported by Ye et al. (2013). They also investigated the presence of nano structure in high rank coals like bituminous coal, anthracite and coke. 
Structural parameters of coals such as aromaticity, coal rank, total number of carbon atoms per aromatic lamellae, lateral size and stacking height are essential in characterizing the graphene layers in coal (Saikia et al. 2007; Manoj and Kunjomana 2012; Manoj 2014a; Takagi et al. 2004). Sonibare et al. (2010) determined the structural parameters of coal by XRD, Raman and FTIR spectroscopy. Reported study revealed that coal comprises of turbostratic structure with some quantity of disordered amorphous carbon. Tuinstra and Koenig (1970) proposed that defect to graphite ratio varies inversely with lateral size. Ferrari and Robertson (2004) describes the importance of D, G and 2D bands and its dependence in structure, intensity and total number of layers in characterizing carbonaceous product. The structure of preformed graphene layers in coal is far from complete understanding due to its complexity and non-uniformity. Tools such as Fourier transform spectroscopy (FTIR), X-ray diffraction (XRD), scanning electron microscopy (SEM) with EDS and Raman spectroscopy have been used to investigate the nanocarbon structure in coal and other carbonaceous product. There are reported study of Indian coals from North and North-Eastern belt by Fourier transform infrared spectroscopy (FTIR), XRD, Transmission electron microscopy (TEM) and Raman spectroscopy by few research group (Binoy et al. 2009; Maity and Mukherjee 2006; Das et al. 2016).

FTIR spectroscopy is a widely used tool elucidating the main functional groups in coal by many researchers $(\mathrm{Li}$ et al. 2015; Manoj 2014b; Binoy et al. 2009). Ample work has been reported by many research group on the role of XRD technique in studying the aromaticity of coal (Takagi et al. 2004; Manoj and Kunjomana 2012). Raman spectroscopy and deconvolution of spectra of coal to identify functional groups and structure has gained popularity very recently ( $\mathrm{Li}$ et al. 2006; Manoj 2014a; Li et al. 2015). These techniques are complimentary techniques and support each other in proper structural elucidation of heterogeneous coal samples.

Recent research indicated the presence of graphite like nano clusters in the coal (Zhou et al. 2012; Binoy et al. 2009; Das et al. 2016; Manoj and Kunjomana 2014; Dong et al. 2014). These preformed clusters could be separated and extracted from coal through some facile approaches, such as chemical oxidation and centrifugation. There are less investigation on the preformed nanostructure present in low rank coals, especially South Central and Godavari coals. Presently, there are less work on the utility of advanced characterization tools in understanding the carbon nanostructure in the coal. The main motive behind the present study is to obtain the structural parameters of nano carbon three different coals using the X-ray analysis, FTIR and Raman analysis investigations. UV-Visible spectroscopy, SEM coupled with energy dispersive spectroscopy is also used in the investigation to validate the results.

Herein we report a facile method to synthesize the mixed phase nanometer-sized graphene nanostructures from amorphous materials like sub-bituminous coal, bituminous coal and high volatile bituminous coal. In this investigation we also aim to report a comprehensive study of nanostructure in coal by collating the information obtained from advanced characterization tools. Demineralization of the coal was carried out with different concentration of the leachant to understand its effect on grain size, stacking and modification of functional group.

\section{Materials and methods}

About $5 \mathrm{~g}$ of raw sub-bituminous coal sample (GX-Godavari basin), High volatile bituminous coal (Korba Coal$\mathrm{KX}$ ) and Bituminous coal (Bihar) were extracted with $50 \mathrm{ml}$ of $\mathrm{HF}$ (G4), slurried in a beaker and stirred in a magnetic stirred for $1 \mathrm{~h}$ at $30^{\circ} \mathrm{C}$. Later, mixture was allowed to settle down and the residual coal was suspended in a column of distilled water for a day, which was filtered again to remove absorbed impurities and organic pollutants. The filtrate was dried at a temperature of $80^{\circ} \mathrm{C}$ and various analytical methods were carried out to characterize the product.

Proximate analysis (by standard methods) and CHNS analysis (for $\mathrm{C}, \mathrm{O}$ and $\mathrm{H}$ detection) were obtained and presented in Table 1. The samples obtained before and after chemical leaching treatment and sonication were analyzed using various structural and morphological characterization techniques such as XRD, Raman spectroscopy, FTIR spectroscopy, electron dispersive spectroscopy

Table 1 Proximate analysis of chemical leached coal

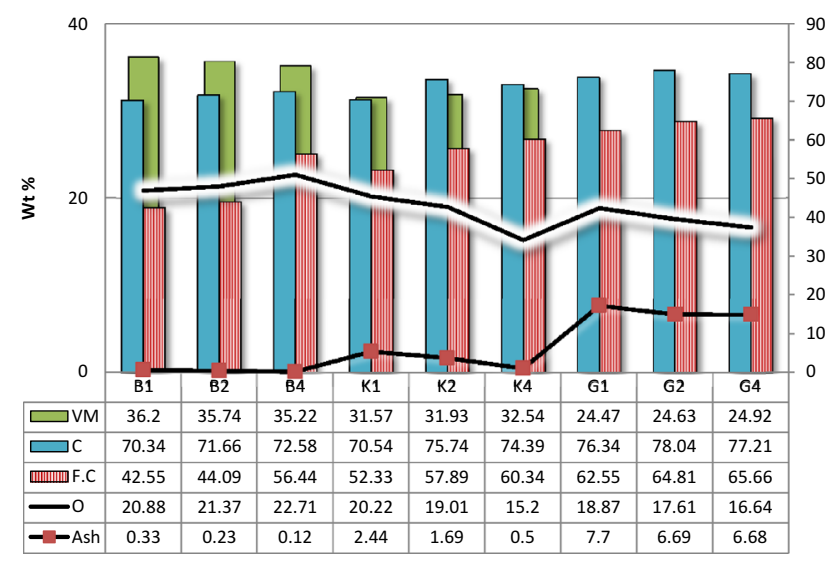


(EDS), SEM and UV-Vis-NIR spectroscopy. X-ray diffractogram of the sample was obtained using a Bruker AXS D8 Advance X-ray Diffractometer. Raman measurements were performed at a wavelength of $514.5 \mathrm{~nm}$ using Horiba LABAM-HR spectrometer. The FTIR spectra were obtained using a Shimadzu FTIR-8400 spectrometer and the microscopic and EDS analyses of the samples were done by means of JSM-6360 A (JEOL) system operated at $20 \mathrm{kV}$. UV-Visible and near-IR spectroscopic investigations were done with the aid of a Cary 500 spectrometer.

The study on X-ray scattering from coal has paramount importance, as it enables quantification of low and high temperature ash as well as mineral content. The grain size $L_{c}$ and $L_{a}$ along $c$ and $a$-axes, is calculated from the (002) and (100) reflections respectively, using Scherer's formula (Eqs. 1, 2). The grain size gives an indication of the number of layers in the stacking.

$L_{a}=\frac{1.84 \lambda}{B_{a} \cos \varphi_{a}}$

$L_{c}=\frac{0.89 \lambda}{B_{c} \cos \varphi_{c}}$

where $\lambda$ is the wavelength of radiation used, $B_{a}$ and $B_{c}$ are the full width half maxima of (100) and (002) peaks in radians, $\varphi_{a}$ and $\varphi_{c}$ are the corresponding scattering angles.

The number of aromatic lamellae can be found using the relation:

$N=\frac{\mathrm{L}_{002}+\mathrm{d}_{002}}{\mathrm{~d}_{002}}$

The average count of carbon atoms per aromatic lamellae $(n)$ is estimated as:

$n=0.32 N^{2}$

The procedure was repeated with different concentrations of HF (20\% and 10\%-G2 and G1) and different samples of various ranks (high volatile bituminous coalBX, B4 B2 and B1 and bituminous coal-KX, K4, K2 and $\mathrm{K} 1)$.

\section{Results and discussion}

\subsection{Proximate and ultimate analysis}

One of the prime component for elucidation of coal rank are its elemental composition mainly carbon. Table 1 shows the proximate analysis of the selected virgin coal and its demineralized products. The fixed carbon has been increased from $45.66 \mathrm{wt} \%$ to $68.89 \mathrm{wt} \%$, accompanied by a reduction of volatile matter from $36.90 \mathrm{wt} \%$ to $24.26 \mathrm{wt} \%$. In the present work, the ash in bituminous coal was reduced from $12.87 \mathrm{wt} \%$ to $0.1 \mathrm{wt} \%$ along with an increase of $16 \%$ in fixed carbon by leaching. The ash content was lowered to $3.06 \mathrm{wt} \%$ (sub-bituminous coal) and $0.1 \mathrm{wt} \%$ (for high volatile bituminous coal sample) as evident in Table 1, eliminating silicate and aluminum minerals completely (as evident from the EDAX analysis). According to van Krevelen (1993) particular organic matters present in coal beds are classified based on $\mathrm{H} / \mathrm{C}$ and $\mathrm{O} / \mathrm{C}$ atomic ratio (Table 2) The $\mathrm{H} / \mathrm{C}$ and $\mathrm{O} / \mathrm{C}$ atomic ratios decrease with increased thermal maturation of organic matter, which indicates the types of kerogen and maceral types present in the coal. $\mathrm{H} / \mathrm{C}$ ratio and $\mathrm{O} / \mathrm{C}$ ratio is found to be varies from 0.03 to 0.07 and 0.20 to 0.35 . This low value indicates that vitrinite (humic organic matter) is the major organic component and is the type III kerogen (van Krevelen 1993). The stacking height (Lc) is ranging from 1.99 to $2.39 \mathrm{~nm}$ while the $\mathrm{H} / \mathrm{C}$ ratio is found to be ranging from 0.028 to 0.11 . The value of these two parameters are strongly dependent on the aromaticity (fa). As the concentration of the leachant increases, the $\mathrm{H} / \mathrm{C}, \mathrm{O} / \mathrm{C}$ and $\mathrm{Lc}$ value decrease confirming the chemical induced orientation of carbon layers in coal.

\subsection{UV-Vis-NIR spectroscopic analysis}

The UV-Visible spectrum of G1H, L1H and B1H is as portrayed in Fig. 1. UV-Visible spectra of carbon nanostructures generally exhibit a broad $\pi-\pi^{*}$ peak, located at around 200-250 $\mathrm{nm}$ which is due to existence of $\mathrm{sp}^{2}$ hybridisation. This broad peak merges with a long wavelength tail of the $\sigma-\sigma^{*}$ band due to $\mathrm{sp}^{3}$ carbon sites (Manoj 2015). The absorbance peak observed at $240.99 \mathrm{~nm}$ in the Indian coal is related to the $\pi-\pi^{*}$ transitions which is due to the two kinds of conjugative effect.

Table 2 Structural parameters of coal from X-ray analysis

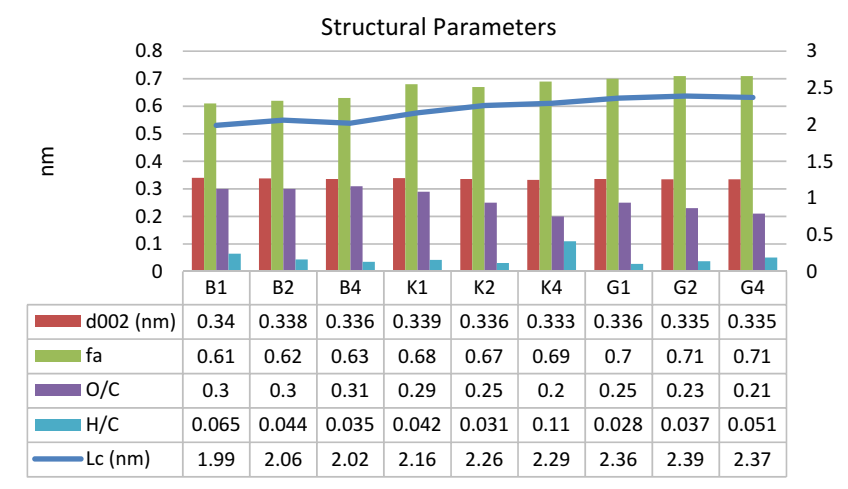




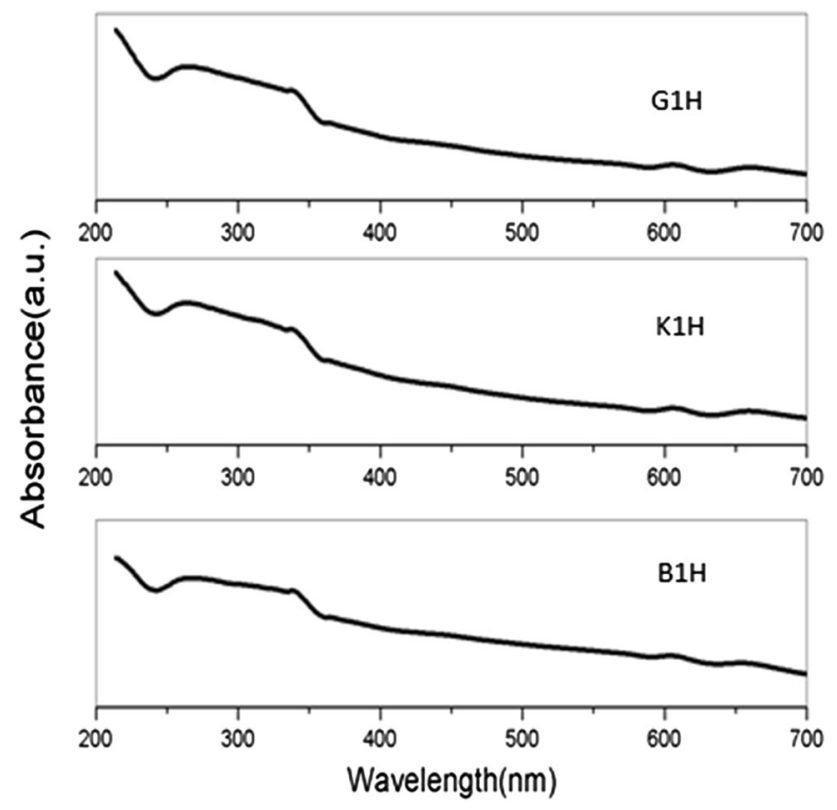

Fig. 1 UV-Visible spectrum of carbon materials in coal

Primarily it is related to the nanometre scale $\mathrm{sp}^{2}$ clusters and secondly it arises due to the linking of chromophore such as $\mathrm{C}=\mathrm{C}, \mathrm{C}=\mathrm{O}, \mathrm{C}-\mathrm{O}$ bonds. The shoulder at $336.16 \mathrm{~nm}$ is attributed to the $\mathrm{n}-\mathrm{n} *$ transition $\mathrm{C}=\mathrm{O}$ bond. The small bump at around $650 \mathrm{~nm}$ is due to $\pi-\pi^{*}$ electronic transitions of the poly nuclear aromatic hydrocarbons, increases with the rank of coal (Osamu 1993; Manoj and Kunjomana 2011; Manoj 2015). This finding is an evidence of the graphitic structure present in the coal sample.

\subsection{X-ray diffraction analysis}

Figure 2 shows the XRD profile of as received sub-bituminous (GX) coal. The peaks observed at 12.4, 20.5 and $33.3^{\circ}$

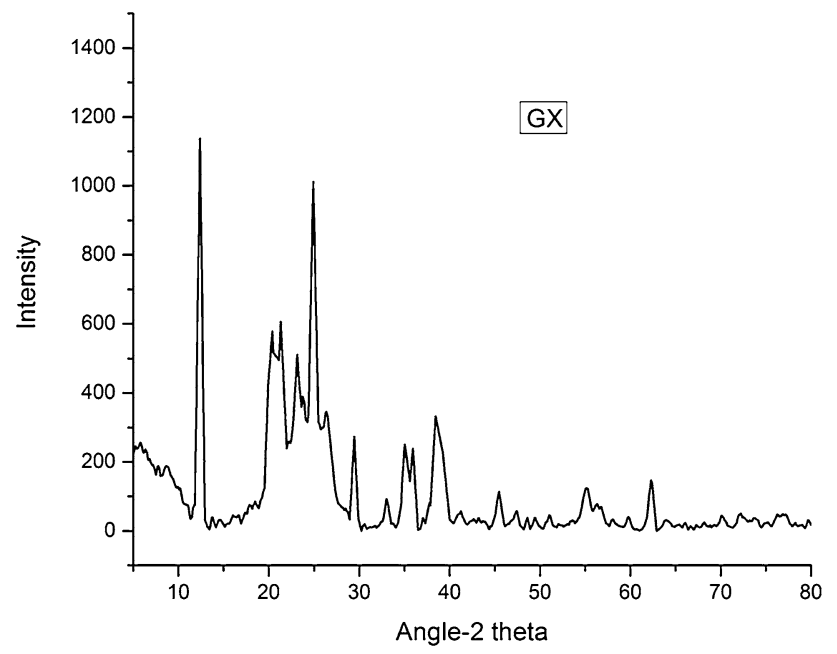

Fig. 2 XRD pattern of virgin sub-bituminous coal are assigned to kaolinite $\left.\left(\mathrm{Al}_{2} \mathrm{Si}_{2} \mathrm{O}_{5}(\mathrm{OH})_{4}\right)\right)$, while, that at $29.3^{\circ}$ is due to the presence of dolomite in the samples ( $\mathrm{Wu}$ and Steel 2007). Except for the intense sharp spikes corresponding to inorganic components such as kaolinite, pyrite, quartz, crystoballite and mullite, the strong diffraction maxima at $25.8^{\circ}$ is attributed to crystalline carbon in coal samples. The weak peak at $43^{\circ}$ is ascribed to (101) plane reflection of graphite (Manoj 2015; Ramya et al. 2013).

The XRD profiles of selected demineralized coal samples (Samples leached with $20 \% \mathrm{HF}$ ) are represented in Fig. 3, which exhibits intense background, confirming highly disordered amorphous carbon. The coals contain graphite-like structure indicated by the presence of a broad (002) peak at $\sim 25.5^{\circ}$ and weak (010) peak in the neighbourhood of (100) plane at $\sim 42.3^{\circ}$. This is due to the random layer lattice structure of crystallites in coal $(\mathrm{Lu}$ et al. 2001; Binoy et al. 2009; Takagi et al. 2004; Manoj 2014b, 2015; Boral et al. 2015).

The diffraction profiles showed a clear asymmetric (002) peak, arises due to existence of $\gamma$ band. The occurrence of this band $\sim 20^{\circ}$ arises owing to saturated structures like aliphatic side chains (Binoy et al. 2009; Maity and Mukherjee 2006; Manoj and Kunjomana 2012). The position of $\gamma$ band is broadened and shifted to a higher angle after leaching. This is due to the ordering of carbon in the coal matrix. The (002) band is an indicator of lattice ordering, while the $\gamma$ band echoes the saturated structure.

In the present study, an attempt was made to evaluate the aromaticity in coals by quantitative X-ray analysis. Aromaticity $\left(f_{a}\right)$ is used as a measure to describe the ratio between the carbon atoms in aliphatic side chains and those in aromatic rings. As $f_{a}$ increases, $d_{002}$ decreases, whereas the rank $\left(\mathrm{I}_{26} / \mathrm{I}_{20}\right)$ increases. Coal becomes more condensed as a result of chemical-induced orientation, and the value of $d_{002}$ approaches that of graphite $(0.335 \mathrm{~nm})$. The degree of graphitization of coal was assessed (Fig. 4) and was found to increase with rank and with concentration of HF. This correlation is attributed to the ordering of carbon layers induced by chemical leaching (Zhou et al. 2012).

The ratio, $\mathrm{I}_{20} / \mathrm{I}_{26}$ obtained from XRD analysis was plotted against $L_{a}$ values obtained using Eq. 1 (Fig. 5). As coals have extremely disordered graphite like structure, two important factors are to be taken into consideration. First, the $\mathrm{T}-\mathrm{K}$ relation is true only for confined $\mathrm{sp}^{2}$ structure, if its imperfection is caused by spatial confinement of graphitic plane and nanocrystals of uniform size (Tuinstra and Koenig 1970). The second factor is relevant for strongly distorted graphitic lattice whose defect peak $(\gamma)$ is prominent. The breathing mode of $\mathrm{A}_{1 \mathrm{~g}}$ symmetry is forbidden in graphitic plane and active when disorder is present. The intensity of disorder is inversely proportional to $L_{a}$ and is related to the presence of six fold aromatic structure in graphite. As the disorder in coal increases, a large number of clusters become 

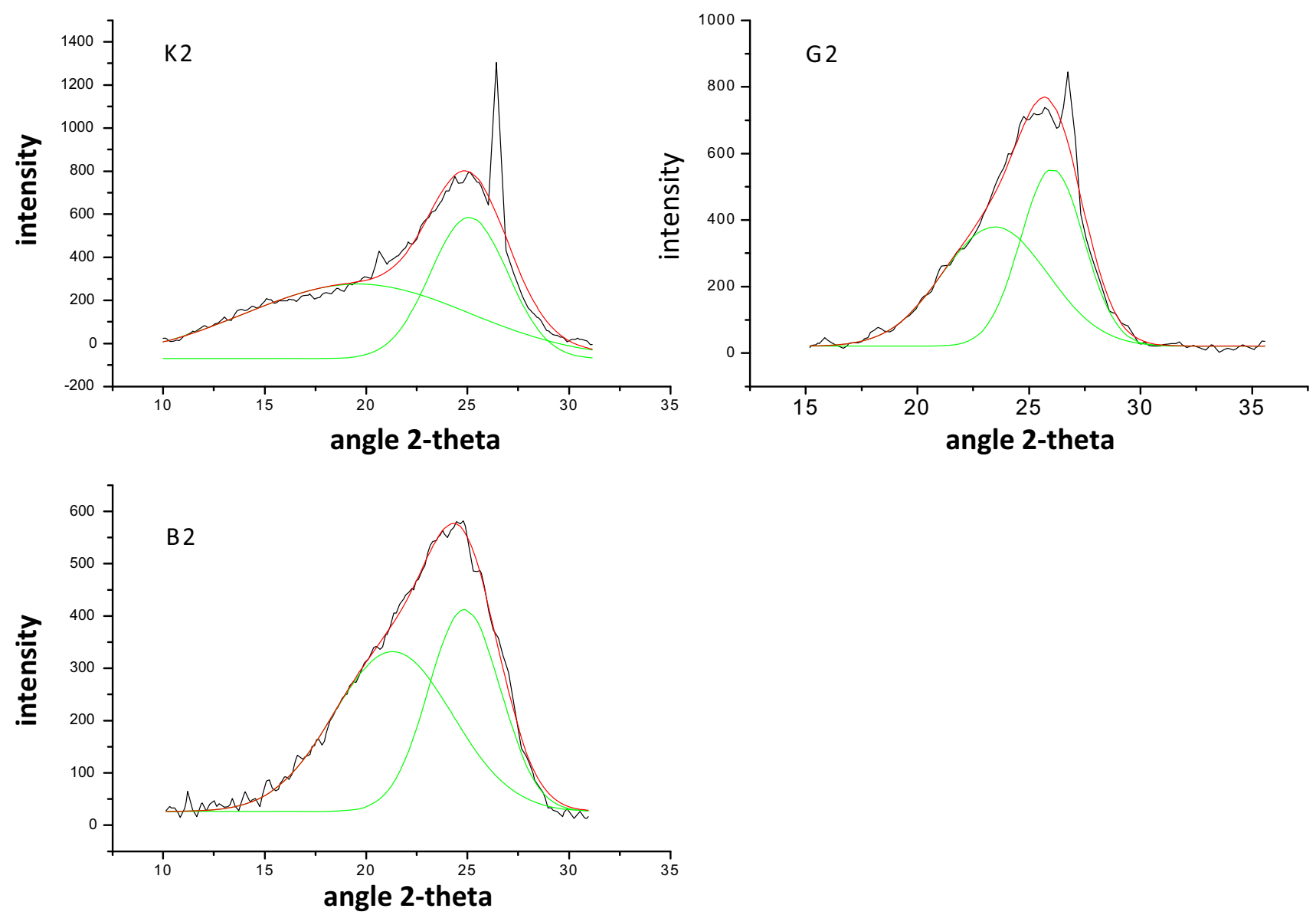

Fig. 3 XRD profiles of HF treated coal (20\%)

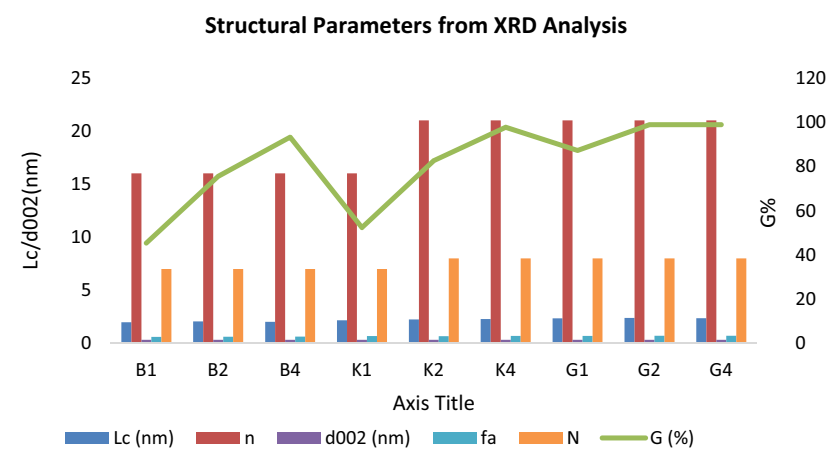

Fig. 4 Structural parameters determined from curve fitting of X-ray profile

smaller and distorted, until they open up. As a result, $\mathrm{I}_{20}$ decreases with respect to $\mathrm{I}_{26}$ and the T-K relation will no longer be valid. The present research findings revealed that, with the transition of coal from low to high rank, the dependency of $I_{20} / I_{26}$ on $L_{a}$ is saturated, due to the increase in average size of $\mathrm{sp}^{2}$ nano clusters. It indicates that in low rank coals, the lattice size and particle size are less. Low

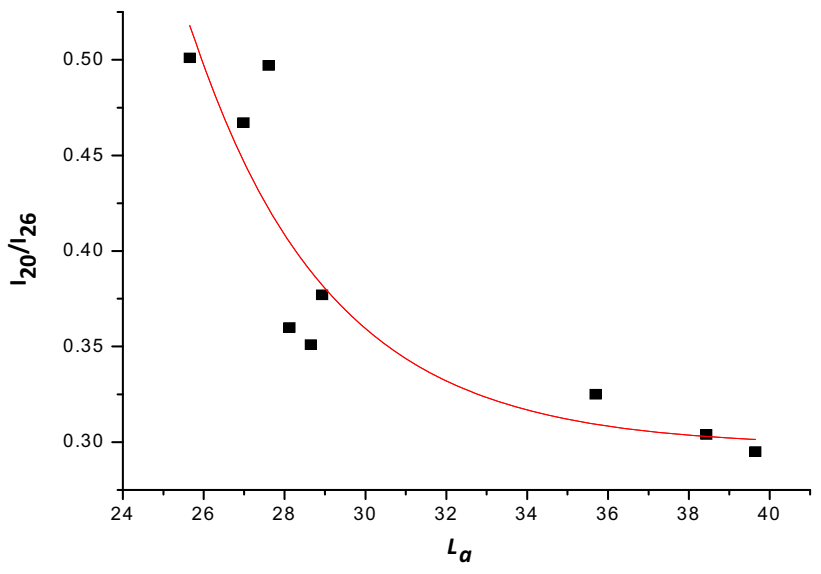

Fig. 5 Variation of I20/I26 ratio with $L_{a}$ (Lu et al. 2001)

rank coals are the ideal precursor for the synthesize of nano carbon and quantum dots

The $\mathrm{H} / \mathrm{C}$ ratio plotted against aromaticity shows a linear fall, confirming the graphitization of coal on leaching (Fig. 6). In the present study, the position of graphite and defect bands as well as their half width and the dependence 


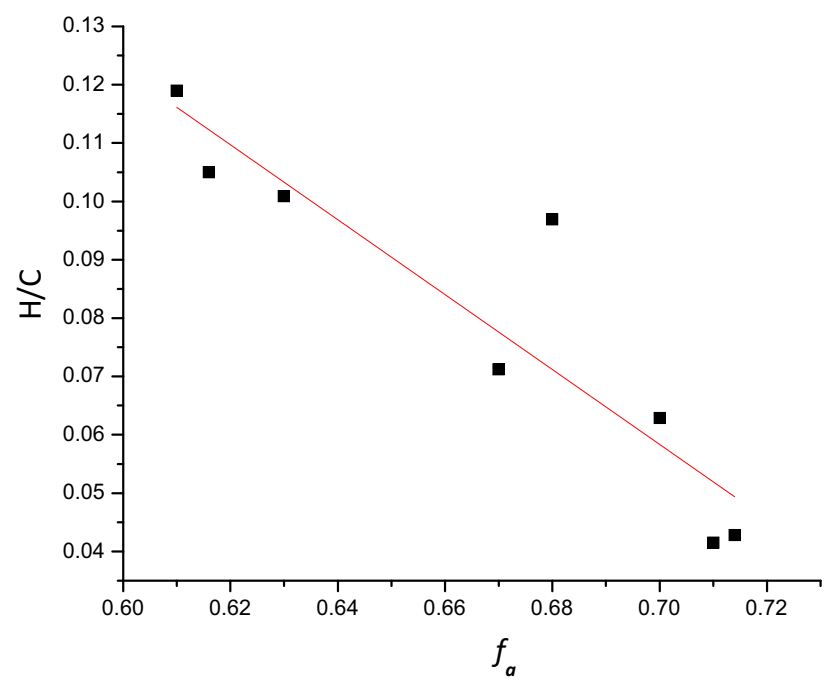

Fig. 6 Dependence of $\mathrm{H} / \mathrm{C}$ atomic ratio on aromaticity, $f_{a}$

on rank appreciably match with the values obtained by other research groups (Li et al. 2015).

\subsection{Vibrational spectroscopic analysis}

\subsubsection{Spectral analysis by spectral deconvolution}

In order to confirm the detailed information about the structure of coal derived from X-ray analysis, Raman spectra of coal sample was recorded and presented in Fig. 7 and Table 3. Raman spectroscopy provides information about the crystalline and molecular structure in coal. This provides details about imperfection in the graphitic lattice like defect, grain boundaries, vacancies or other types of defects. For an amorphous materials like coal, the graphitic band (G-band) and defect band (D-band) are broad and

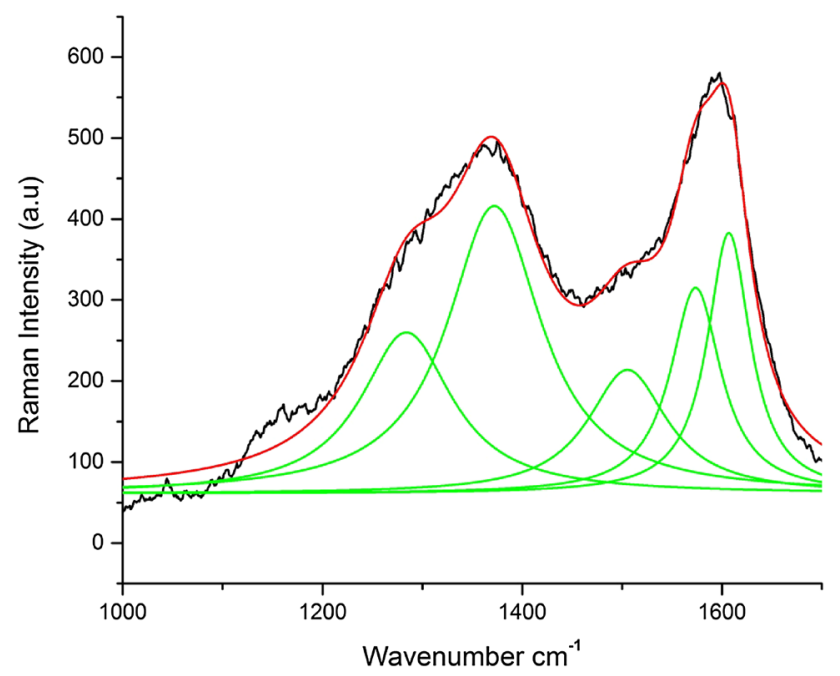

Fig. 7 Curve fit for the first order Raman spectrum of sub-bituminous coal overlap with each other. Thus, deconvolution of the Raman spectra is essential. The first order spectrum was deconvoluted to five bands namely, G, D1 (D), D2 (D'), D3 and D4. The dominant Raman band are presented in Table 2. It is suggested that, the observed $G$ peak $\left(1585 \mathrm{~cm}^{-1}\right)$ and the D2 band arises from graphitic lattices (Manoj 2014a; Sadezky et al. 2005). The D3 band $\left(\sim 1500 \mathrm{~cm}^{-1}\right)$ originates from the amorphous carbon content of coal which forms Gaussian distribution. This band is originated due to the amorphous carbon on interstitial sites in the distorted carbon lattice of coal. The shoulder peak near the $\mathrm{D}$ band is designated as $\mathrm{D}$ band $\left(\sim 1280 \mathrm{~cm}^{-1}\right)$ and which arises due to $\mathrm{sp}^{2}-\mathrm{sp}^{3}$ bonds or $\mathrm{C}-\mathrm{C}$ and $\mathrm{C}=\mathrm{C}$ stretching vibrations of polyene-like structures. Ferrari and Robertson (2004) attributed the origin of these two peaks to the sum and difference of $\mathrm{C}=\mathrm{C}$ stretching and $\mathrm{CH}$ wagging of the transpolyacetylene in nano-crystalline diamond. They also could originate from the nano graphitic structure. This suggest the possibility that, the observed peak in the coal sample is due to the existence of finite size of crystalline and defect induced carbon.

A broad similarity in the peak position is noticed in the spectrum of bituminous coal and sub-bituminous coal. The ratio of defect to graphitic band $\left(\mathrm{I}_{\mathrm{D}} / \mathrm{I}_{\mathrm{G}}\right)$ is found to be 0.84 and 0.86 for the bituminous and sub-bituminous coal respectively. This is a measure of the disorder in the graphitic layer of the coal which is in good agreement with other reported study on graphitic materials (Ramya et al. 2013; Mohan et al. 2016). These finding are consistent with the XRD analysis obtained for the coal samples showing the evolution of coal structure as function of fraction of amorphous carbon, aromaticity and crystallite size. Eckmann et al. (2012) reported three types of defects in graphene system with the aid of Raman spectroscopy. For hoping defect the ratio of $\mathrm{I}_{\mathrm{D}} / \mathrm{I}_{\mathrm{D}^{\prime}}\left(\mathrm{I}_{\mathrm{D} 1} / \mathrm{I}_{\mathrm{D} 2}\right)$ is about 10 while for onsite defect it is about 1.3. In the present investigation, it is $\sim 1.2$ confirming the on-site defect in the carbon layers of coal. This arises due to the out-of plane atoms bonded to carbon atoms describing the $\mathrm{sp}^{3}$ hybridized phase.

To understand the influence of defects in the structure of coal, the 2D region is deconvoluted into constituent peaks (Fig. 8). The 2D band is de-convoluted and have 4 peaks, the intense $G^{*}, G^{\prime}, D+D^{\prime}$ and $2 D^{\prime}$ band at 2445, 2720, 2925 and $3160 \mathrm{~cm}^{-1}$. This is attributed to the splitting of $\pi$ electron dispersion energies caused by the interaction between neighboring graphitic planes (Manoj 2015; Sadezky et al. 2005). This band also could be due to the overtone of the $\mathrm{D}$ band and credited to the induced disorder in the graphene layers. The position of the $G^{\prime}$ band depends on the number of layers and stacking order of the graphite sample. For a perfectly stacked few layer graphene (about 6-8 layers), the 2D peak $\left(\mathrm{G}^{\prime}\right.$ peak) exhibits two peak profile (Manoj 2015; Ramya et al. 2013). As the disorder 
Table 3 Assignment of Raman bands in Indian coals

\begin{tabular}{llll}
\hline Band position $\left(\mathrm{cm}^{-1}\right)$ & Functional group & Band name & Bond type \\
\hline 1200 & C=C stretching vibrations/finite size crystallites & D4-band & D1-band \\
1280 & Hexagonal diamond carbon & D3-band & $\mathrm{sp}^{2}-\mathrm{sp}^{3}$ \\
$1350-1376$ & Defected graphite & G-band & $\mathrm{sp}^{2}-\mathrm{sp}^{3}$ \\
$1500-1505$ & Amorphous carbon structure & $\mathrm{D}^{\prime}$ band (D2-band) \\
$1571-1590$ & Graphitic like carbonyl group & & $\mathrm{sp}^{2}$ \\
$1600-1610$ & Defect in graphitic plane & $\mathrm{G}^{*}$ & $\mathrm{sp}^{2}$ \\
2445 & First overtone of D4 band & $\mathrm{G}^{\prime}(2 \mathrm{D})$ \\
$2690-2720$ & First overtone of D1 band & $\mathrm{D}^{2}+\mathrm{D}^{\prime}(\mathrm{D}+\mathrm{G})$ \\
2925 & 2D overtone & 2D $^{\prime}$ \\
3160 & Overtone of D2 $\left(\mathrm{D}^{\prime}\right)$ band & \\
\hline
\end{tabular}

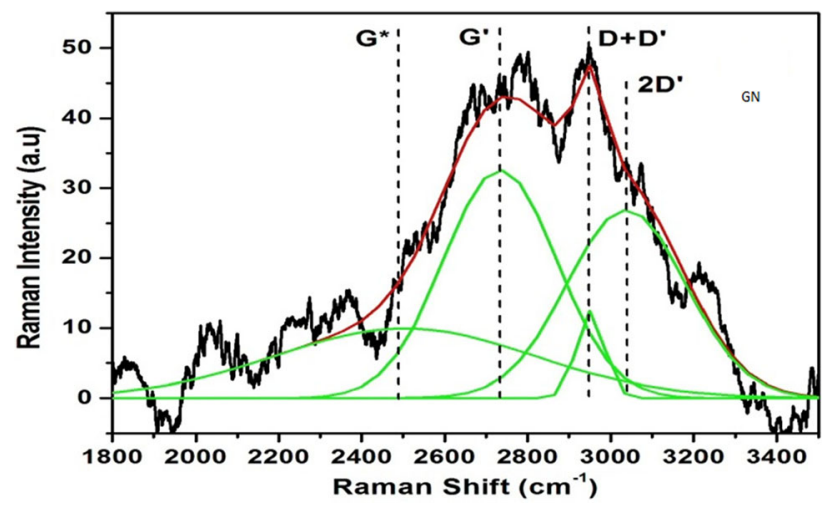

Fig. 8 Curve fit for the second order Raman spectrum of subbituminous coal

increases, the $\mathrm{G}^{\prime}$ shoulder shift upwards and finally merges into $G^{\prime}$ band and results into single $2 \mathrm{D}$ band ( $\mathrm{G}^{\prime}$ band). This is due to the advance of turbostraticity and the disappearance of three dimensional ordering. In polycrystalline carbonaceous materials, having nano carbon atoms at the boundary of the graphene plane act as the source of the defect band. The band at $2720 \mathrm{~cm}^{-1}$ is originates from the first overtone of the D1 band while band at $3160 \mathrm{~cm}^{-1}$ is assigned to the first overtone of $\mathrm{D} 2$ band or $\mathrm{G}+\mathrm{D}^{\prime}$ band. The absorption at $2445 \mathrm{~cm}^{-1}$ could be due to first overtone of a Raman-inactive graphitic lattice vibration mode at $\sim 1280 \mathrm{~cm}^{-1}$ (Manoj 2014b, 2015). The $\mathrm{D}+\mathrm{D}^{\prime}$ bands are broadened resulting in a sharp curve in the $2 \mathrm{D}$ region. From the second order spectrum, it is evident that in coal about 6-8 stacked graphene layers are formed with leaching as evident from the X-ray analysis (Elcey and Manoj 2016; Mohan et al. 2016).

The identification of most prominent bands of the FTIR spectra of both virgin bituminous coal and its chemical leached products are presented in Fig. 9 and Table 4. Intense bands were observed at $540 \mathrm{~cm}^{-1}$, resulting from clay and silicate minerals and the peaks at 3620 and $3700 \mathrm{~cm}^{-1}$ were assigned to kaolinite and illite minerals (Manoj and Elcey 2010; Manoj 2014a). As expected, the intensity of all bands decreased with increasing concentration of HF. The asymmetric and symmetric $-\mathrm{CH}_{2}$ stretching appears strongly at 2926 and $2853 \mathrm{~cm}^{-1}$, while an asymmetric band appears near $1460 \mathrm{~cm}^{-1}$ in the infrared spectrum. The scissoring mode of $-\mathrm{CH}_{2}$ group gives rise to a characteristic weak band near $1460 \mathrm{~cm}^{-1}$, which overlaps with $-\mathrm{CH}_{3}$ bending normally present in low rank coals. A great abundance of $\mathrm{C}=\mathrm{O}$ and $\mathrm{C}-\mathrm{O}-\mathrm{R}$ structures was noted, as revealed by the intensity of peaks in the $1800-1000 \mathrm{~cm}^{-1}$ region. This zone of oxygen containing functional groups was characterized by a very intense peak at $1620 \mathrm{~cm}^{-1}$, which was either attributed to $\mathrm{C}=\mathrm{O}$ or $\mathrm{C}=\mathrm{C}$ aromatic ring stretching (Manoj and Elcey 2010; Manoj 2014b). The C=C bands between the $\mathrm{C}-\mathrm{O}$ and $\mathrm{C}=\mathrm{O}$ groups, were not definitely distinguished, since low rank coals have high oxygen content and were almost masked by the $\mathrm{C}=\mathrm{C}$ structure.

The carbonyl and aromatic $\mathrm{C}=\mathrm{C}$ ring stretching vibration showed lower intensity with leaching. The $1350-1000 \mathrm{~cm}^{-1}$ region is very complex, because of the contribution of many functional groups and mineral matter present. On demineralization, all the mineral bands disappeared, confirming the elimination of minerals like silicates and quartz and formation of graphite like structure (Wu Dun et al. 2013; Manoj and Kunjomana 2014).

\subsection{SEM-EDS analysis}

SEM of the carbonaceous structure and minerals in coal are presented in Figs. 10, 11, 12 and 13. The surface morphology revealed non uniform topography with minerals embedded in carbon matrix. The EDS analysis revealed the presence of carbon, hydrogen, oxygen, nitrogen, traces of sulphur, silicon and aluminum (Al: $0.9 \mathrm{wt} \%$; $\mathrm{Si}: 1.21 \mathrm{wt} \%$ ) as major elements. Luminous and non-luminous features 


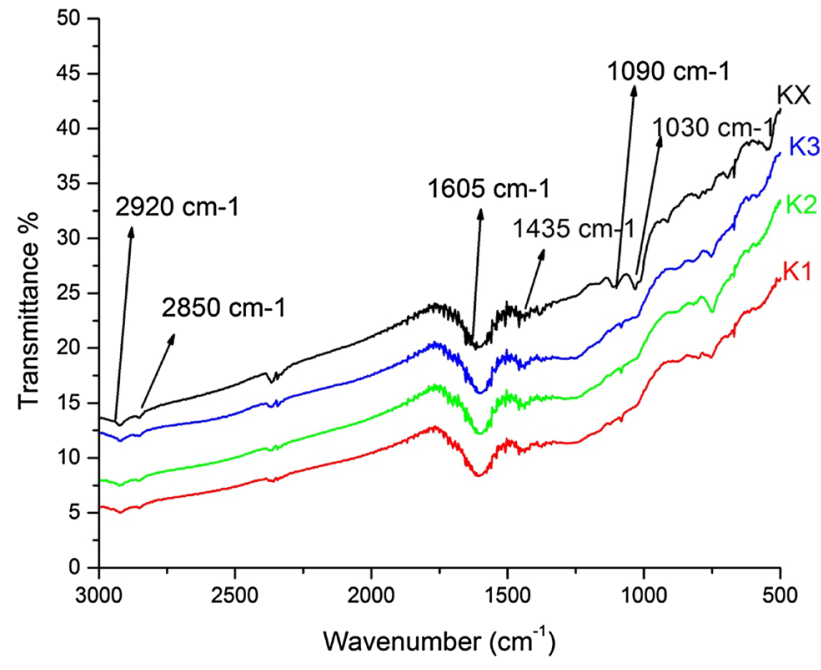

Fig. 9 FT-IR spectra of bituminous coal and leached products

Table 4 FTIR band assignment of the prominent functional groups in coal

\begin{tabular}{|c|c|}
\hline $\begin{array}{l}\text { Wavenumber } \\
\left(\mathrm{cm}^{-1}\right)\end{array}$ & Functional group \\
\hline $3620-3700$ & Kaolinite/illite minerals \\
\hline $3080-3000$ & Aromatic nucleus $/ \mathrm{C}-\mathrm{H}$ stretching vibration \\
\hline $2980-2950$ & $\begin{array}{l}\text { Aliphatic } \mathrm{CH}_{3} \text { asymmetric stretching } \\
\text { vibration }\end{array}$ \\
\hline 2920 & $\begin{array}{l}\text { Aliphatic } \mathrm{CH}_{2} \text { asymmetric stretching } \\
\text { vibration }\end{array}$ \\
\hline $1620-1580$ & Aromatic nucleus $(\mathrm{C}=\mathrm{C})$ \\
\hline $1500-1470$ & $\mathrm{C}-\mathrm{C}$ stretching \\
\hline 1450 & $\mathrm{CH}_{3} / \mathrm{CH}_{2}$ chain \\
\hline $1350-1380$ & $-\mathrm{CH}_{2}$ bending \\
\hline $1300-1000$ & Phenolic deformation \\
\hline $900-700$ & Aromatic structure \\
\hline 540 & Silicate minerals \\
\hline
\end{tabular}

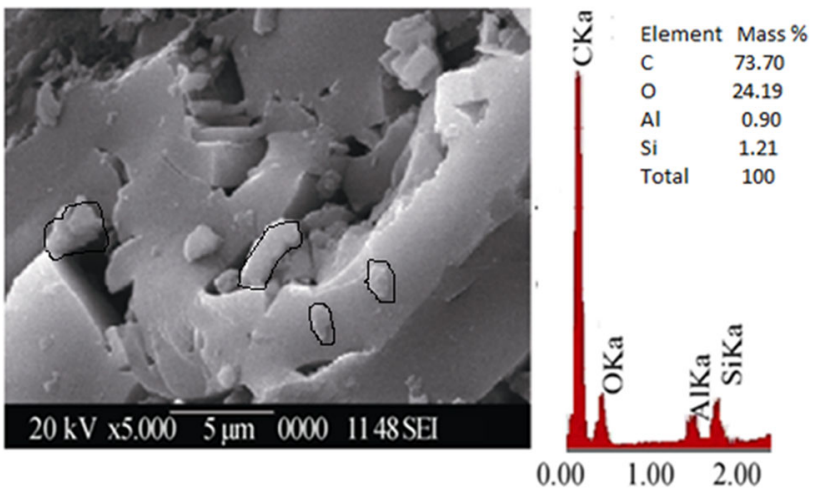

Fig. 10 Observation of minerals in bituminous coal (KX)

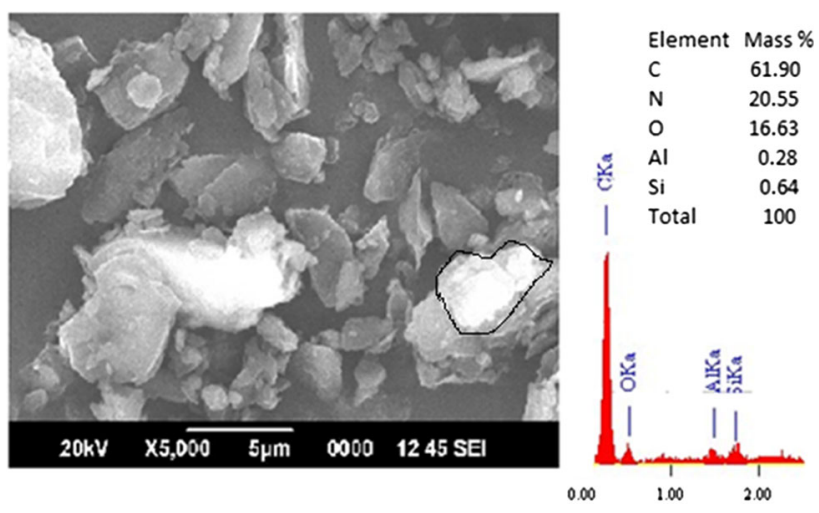

Fig. 11 Observation of minerals in sub-bituminous coal (GX)

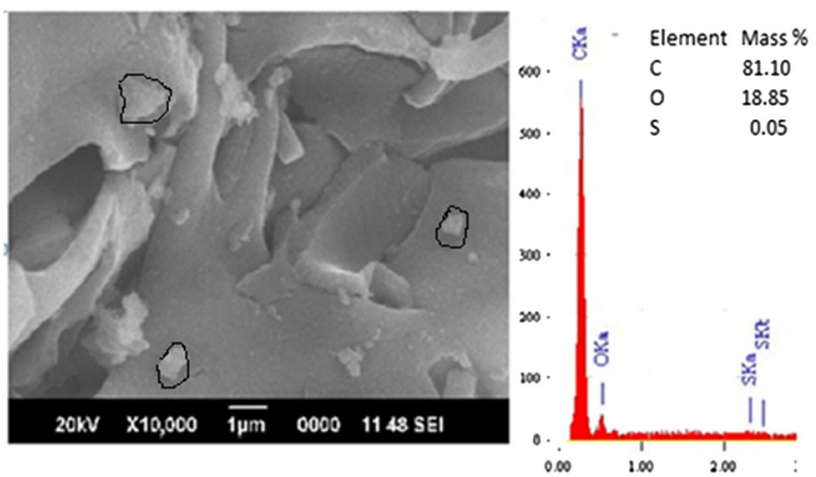

Fig. 12 Observation of minerals in HF treated bituminous coal (K4)

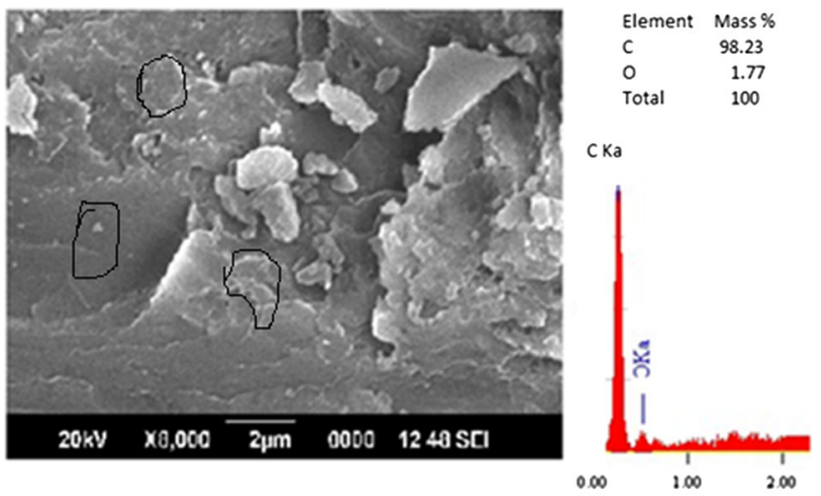

Fig. 13 Observation of minerals in HF treated sub-bituminous coal (G4)

were also observed in the matrix. Large particles of $10 \mu \mathrm{m}$ size were identified as quartz and kaolinite, whereas those with a few $\mu \mathrm{m}$ were recognized as pyrite by EDS spot analysis. They occur in the virgin sample as minute grains and are finely disseminated throughout.

The SEM image of virgin bituminous coal (KX) and subbituminous (GX) coal are given in Figs. 10 and 11. The elemental composition confirmed the presence of minerals 
like $\mathrm{Si}(1.21 \mathrm{wt} \%), \mathrm{Al}(0.90 \mathrm{wt} \%)$ and traces of calcium. On treating the sample with HF solution $(40 \%)$, particles of kaolinite and bassanite were extensively removed, showing a significant decrease in surface brightness (Fig. 13). Chemical leaching thus resulted in morphological changes to the surface by removing the inorganic minerals. The chemical composition indicated that, the surface consists of $98.23 \mathrm{wt} \%$ carbon and $1.77 \mathrm{wt} \%$ oxygen for sub-bituminous coal (Fig. 13). The elemental percentages of bituminous sample were found to be 81.1 and $18.85 \mathrm{wt} \%$. Thus, the EDS analysis revealed extinction of silicates, aluminates and calcites in both types of coal (Elcey and Manoj 2013). Formation of layered structure is evident in the SEM micrograph of the leached products confirming the graphitization of coal with leaching. This is in agreement with the $\mathrm{X}$-ray and Raman analysis.

An in-depth investigation was carried out on three Indian coals using a range of advanced analytical techniques focused specifically on extracting structural parameters. Detailed investigations were carried out using FTIR spectroscopy, Raman spectroscopy, and XRD followed by peak deconvolution and data analysis. The investigation revealed the existence of finite size of crystalline and defect induced carbon in Indian coal. The SEM-EDS analysis confirms the stacking of graphene oxide structure in coal with HF leaching.

\section{Conclusions}

The investigation revealed the existence of finite size of crystalline and defect induced carbon in Indian coal. With the transition of coal from low to high rank, the dependency of $\mathrm{I}_{20} / \mathrm{I}_{26}$ on $L_{a}$ is saturated, due to the increase in average size of $\mathrm{sp}^{2}$ nanoclusters. It indicates that in low rank coals, the lattice size and particle size are less and they are the ideal precursor to synthesize of nano carbon and quantum dots. The stacking height $(\mathrm{Lc})$ is ranging from 1.99 to $2.39 \mathrm{~nm}$ while the $\mathrm{H} / \mathrm{C}$ ratio is found to be ranging from 0.028 to 0.11 . The value of this two parameters are strongly dependent on the aromaticity (fa). As the concentration of the leachant increases, the $\mathrm{H} / \mathrm{C}, \mathrm{O} / \mathrm{C}$, interlayer spacing $\left(d_{002}\right)$ and Lc value decreases confirming the chemical induced orientation of carbon layers in coal. The degree of graphitization of coal is also found to increase with rank and with concentration of leachant.

In the UV spectra, absorption peaks at 233,232 and $229 \mathrm{~nm}$ are attributed to the $\pi-\pi^{*}$ transition of $\mathrm{C}=\mathrm{C}$ bonding. In the IR spectrum, a great abundance of $\mathrm{C}=\mathrm{O}$ and $\mathrm{C}-\mathrm{O}-\mathrm{R}$ structures is noted in the $1800-1000 \mathrm{~cm}^{-1}$ region. The intensity ratio of two Raman spectral parameters, D and $G\left(I_{D} / I_{G}\right)$, was found to be less than 1 in all the samples confirming low crystallinity of graphene layers with on site defect. The second order spectrum reveals the formation of about 6-8 stacked graphene layers in coal. The SEM-EDS analysis confirms the presence of flakes of graphene oxide with carbon and oxygen as major constituents.

Open Access This article is distributed under the terms of the Creative Commons Attribution 4.0 International License (http://crea tivecommons.org/licenses/by/4.0/), which permits unrestricted use, distribution, and reproduction in any medium, provided you give appropriate credit to the original author(s) and the source, provide a link to the Creative Commons license, and indicate if changes were made.

\section{References}

Binoy S, Boruah RK, Gogoi PR (2009) A X-ray diffraction analysis on graphene layers of Assam coal. J Chem Sci 121(1):103-106

Boral P, Varma AK, Maity S (2015) X-ray diffraction studies of some structurally modified Indian coals and their correlation with petrographic parameters. Curr Sci 108(3):384-394

Das T, Binoy SK, Baruah BP (2016) Formation of carbon nano-balls and carbon nano-tubes from northeast Indian Tertiary coal: value added products from low grade coal. Gondwana Res 31:295-304. doi:10.1016/j.gr.2015.01.012

Dong Y et al (2014) Graphene quantum dots, graphene oxide, carbon quantum dots and graphite nanocrystals in coals. Nanoscale 6:7410-7415

Eckmann A et al (2012) Probing the effects in graphene by Raman spectroscopy. Nano Lett 12(8):3925-3930

Elcey CD, Manoj B (2013) Demineralization of sub-bituminous coal by fungal leaching: a structural characterization by X-ray and FTIR analysis. Res J Chem Environ 17(8):11-15

Elcey CD, Manoj B (2016) graphitization of coal by bio-solubilization: structure probe by Raman spectroscopy. Asian J Chem 28(7): 1557-1560

Ferrari AC, Robertson J (2004) Resonant Raman spectroscopy of disordered, amorphous, and diamond-like carbon. Phys Rev B 64:075414-1-075414-13

Geim AK (2009) Graphene: status and prospects. Science 324:1530-1534

Li X, Hayashi J, Li CZ (2006) FT-Raman spectroscopic study of the evolution of char structure during the pyrolysis of a Victorian brown coal. Fuel 85:1700-1707

Li K et al (2015) Comprehensive investigation of various structural features of bituminous coals using advanced analytical technique. Energy Fuels 29(11):7178-7189

Lu L, Sahajwalla V, Kong C et al (2001) Quantitative X-ray diffraction analysis and its application to various coals. Carbon 39(12):1821-1833

Maity S, Mukherjee P (2006) X-ray structural parameters of some Indian coal. Curr Sci 91(10):337-340

Manoj B (2014a) Role of Infrared spectroscopy in coal analysis-an investigation. Am J Anal Chem 5(6):367-372

Manoj B (2014b) Characterization of nano-crystalline carbon from camphor and diesel by X-ray diffraction technique. Asian $\mathrm{J}$ Chem 26(15):731-738

Manoj B (2015) Synthesis and characterization of porous, mixed phase, wrinkled, few layer graphene like nanocarbon from charcoal. Russ J Phys Chem A 89(13):2438-2442

Manoj B, Elcey CD (2010) Demineralization of coal by stepwise leaching: a study of sub-bituminous Indian coal by FTIR and SEM. J Univ Chem Technol Metall 45(4):385-390

Manoj B, Kunjomana AG (2011) Analytical study of two differently ranked coals using UV-Vis-NIR spectroscopy. J Min Mater Charact Eng 10(10):905-911 
Manoj B, Kunjomana AG (2012) Study of stacking structure of amorphous carbon by X-ray diffraction technique. Int $\mathrm{J}$ Electrochem Sci 7(4):3127-3134

Manoj B, Kunjomana AG (2014) Systematic investigations of graphene layers in sub-bituminous coal. Russ J Appl Chem 87(11):126-1733

Mohan AN, Ramya AV, Manoj B (2016) Probing the nature of defects of graphene like nano-carbon from amorphous materials by Raman spectroscopy. Asian J Chem 28(7):1501-1504

Osamu I (1993) UV-Visible and Near-IR spectra of heat-treated pitches during mesphase formation. Carbon 31(3):401-406

Ramya K, John J, Manoj B (2013) Raman spectroscopy: investigation of camphor soot: spectral analysis and structural information. Int J Electrochem Sci 8:9421-9428

Sadezky A, Muckenhuber H, Grothe H et al (2005) Raman micro spectroscopy of soot and related carbonaceous materials: spectral analysis and structural information. Carbon 43:1731-1742

Saikia BK, Boruah RK, Gogoi PK (2007) FT-IR and XRD analysis of coal from Makum. J Earth Syst Sci 116:575-579

Sonibare OO, Tobias H, Foly SF (2010) Structural characterization of Nigerian coals by X-ray diffraction, Raman and FT-IR spectroscopy. Energy 35(12):5347-5353
Takagi H, Maruyama K, Yoshizawa N, Yamada Y, Sato Y (2004) $\mathrm{XRD}$ analysis of carbon stacking structure in coal during heat treatment. Fuel 83:2427-2433

Tuinstra F, Koenig JL (1970) Raman spectrum of graphite. J Phys Chem 53:1126-1130

Van Krevelen DW (1993) Coal: typology, physics, chemistry, constitution, coal science and technology, 3rd edn. Elsevier, Amsterdam

Wu Z, Steel KM (2007) Demineralization of a UK bituminous coal using HF and ferric ions. Fuel 86:2194-2200

Wu D, Liu G, Sun R, Fan X (2013) Investigation of structural characteristics of thermally metamorphosed coal by FTIR spectroscopy and X-ray diffraction. Energy Fuels 27:5823-5830

Ye R, Xiang C, Lin J et al (2013) Coal as an abundant source of graphene quantum dots. Nat Commun 4:2943

Zhou Q et al (2012) Graphene sheets from graphitized anthracite coal: preparation, decoration and Application. Energy Fuels 26:5186-5192 